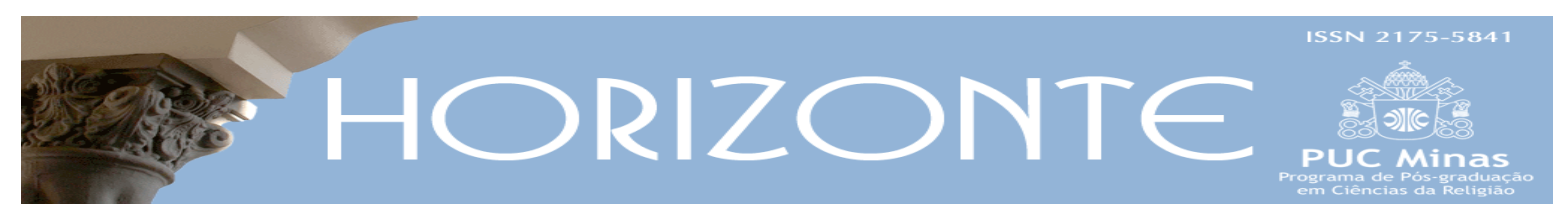

Temática Livre - Artigo original

(c) (i) DOI - 10.5752/P.2175-5841.2019v17n54p1571

\title{
Sibilas: \\ a sobrevivência das profetisas pagãs no mundo cristão
}

\author{
The Sibyls: \\ the survival of Pagan Prophets in the Christian world
}

Maria Cláudia Almeida Orlando Magnani*

\begin{abstract}
Resumo
Os mitos antigos não estão mortos. A partir desta afirmação fundamentada nas obras de autores como Warburg, Jean Seznec, Erwin Panofsky e Fritz Saxl, este trabalho pretende apontar os caminhos históricos que legitimaram a sobrevivência do mito das sibilas no mundo cristão, em sua estreita relação com a astrologia. O paganismo não renasceu após o medievo, mas esteve sempre presente no cristianismo, não só como símbolos, mas como efetiva influência essencial sobre os homens e as suas vidas. Alguns momentos históricos em particular são privilegiados neste caminho, desde os padres apologistas do cristianismo primitivo até o nascimento da ciência moderna. Sibilas e astrologia, como testemunhos "de fora" são presença constante seja na teologia cristã, seja na literatura e na música, ou nas representações plásticas do mundo cristão, que aqui privilegiamos. A sua sobrevivência ou pós-vida (Naschleben) é ora afirmada também pela legitimação de grandes nomes da patrística e da escolástica, e ainda por meio da influência de Albumasar, teólogo muçulmano nascido no século VIII e que faz o elo entre sibilas, astrologia e a Virgem Maria. O que fazem as sibilas nos tetos das igrejas católicas? É esta a pergunta que o presente trabalho pretende, em grande medida, responder.
\end{abstract}

Palavras-chave: Sibilas. Paganismo. Cristianismo. Astrologia. Sobrevivência.

\begin{abstract}
Ancient myths are not dead. Based on this premise, founded on the research of scholars such as Warburg, Jean Seznec, Erwin Panofsky and Fritz Saxl, the intent of this paper is to delineate the historical paths which legitimized the survival of the myth of the Sibyls in the Christian world in its close association with astrology. Paganism was not reborn after the Middle Ages. It has always been an intrinsic element of Christianity, not only symbolically, but also as a direct impact on people and their lives. Some particular moments in history are in this sense noteworthy, from the apologist priests of primitive Christianity to the birth of modern science. The sibyls and astrology, as "outside" witnesses, are a constant presence in Christian theology, literature and music, as well as in artistic representations of the Christian world, which is the focus of this paper. The survival or afterlife (Naschleben) of the sibyls throughout history is further affirmed by the writings of the patristic and scholastic theologians, and also evidenced in the work of Albumasar, the Muslim theologian born in the 8th century, who associates sibyls, astrology and the Virgin Mary. How can we justify the presence of the sibyls on the ceilings of Catholic churches? This is the question that this paper largely intends to address.
\end{abstract}

Keywords: Sibyls. Paganism. Christianity. Astrology. Survival.

Artigo submetido em 31 de julho de 2018 e aprovado em 2 de novembro de 2019.

* Doutora em História da Arte pela UFMG. Professora da Faculdade Interdisciplinar em Humanidades (FIH) e do Programa de PósGraduação em Ciências Humanas (PPGCH) da UFVJM. País de origem: Brasil. E-mail: magnani@redecitel.com.br 


\section{Introdução}

A pergunta mais recorrente de quem ergue os olhos para a abóboda de uma das inúmeras igrejas que são adornadas com sibilas pelo mundo afora é: o que fazem as profetisas pagãs no teto de uma igreja católica? É uma ótima pergunta e a resposta, como todo resultado de uma boa interrogação, é multifacetada e transdisciplinar.

As sibilas estão entre aqueles mitos que tiveram um alcance temporal longo e a sobrevivência em muitos e distintos espaços. Ao longo da história da humanidade, todas as culturas criaram mitos que pretenderam dar respostas às questões fundamentais do ser humano. É nesse contexto mitológico que se inserem as sibilas e seus oráculos, ainda que, do ponto de vista da compreensão do mito, alguns problemas se interponham. Dentre eles, quando se trata do mundo pagão, as sibilas não são entes sobrenaturais (condição concernente aos mitos amplamente aceita pelos eruditos), mas mulheres de carne e osso. Do ponto de vista da cultura judaico-cristã, de acordo com Eliade (1972, p. 06-11), o mito sibilino não é relegado ao campo da falsidade ou da ilusão - como acontece frequentemente com as narrativas que não estão legitimadas ou validadas nos dois testamentos - ainda que não esteja referendado nos livros sagrados. Sobre essa legitimação extraordinária é que me dedico a seguir.

O registro mais remoto dos oráculos sibilinos se dá na Babilônia, migrando daí para a cultura greco-romana, como afirma Peretti (1943, p. 11-12). Na mitologia greco-romana, as sibilas, quando ligadas a um deus, são profetisas de Apolo e têm a função de dar a conhecer os seus oráculos. Como seres mortais, as profetisas faziam o elo entre o profano e o sagrado atendendo à necessidade humana tanto de se comunicar com o transcendente, como de saber dos acontecimentos porvindouros. Como é comum ocorrer nos mitos, várias versões inconciliáveis circulam sobre o momento do surgimento da sibila na Grécia. Baudoin (2012, p. 62-70), entretanto, aponta um momento preciso: a sibila teria aparecido pela primeira vez no século VIII a.C., época na qual ela teria se apresentado como filha de Lamia, por sua vez 
filha de Posseidon, durante as celebrações dos jogos de Corinto. As suas profecias nunca são respostas, mas visões. Potente intermediária entre céu e terra, ela perscruta a obscuridade dos tempos mais remotos e enxerga os futuros mais longínquos. Apesar da estreita conexão entre a lenda e a tradição artístico-literária, não obstante serem substrato uma da outra, essas duas linguagens desenvolvem-se paralelamente, como águas próximas que não se podem unir completamente. Segundo Ferri (2007, p. 56) a lenda da sibila é pura e exclusivamente italiana, enquanto as outras manifestações são europeias em geral, ou quase totalmente europeias. O que interessa aqui, no entanto, é o caráter de universalidade desse mito. A sua forte e diversificada sobrevivência, deve-se, segundo este autor, a um "principium vitae" (FERRI, p. 61) que remete à sua primordial composição humano-religiosa. Assim, mesmo na tradição popular, a sibila, ou ao menos seu nome, permanece até os dias atuais.

Os oráculos sibilinos, adaptados pelos judeus, foram adotados pelos cristãos desde o cristianismo primitivo. Antes dessa incorporação, porém, para os romanos antigos a adivinhação sibilina era estreitamente ligada ao animismo e ao primitivo culto dos mortos. Posteriormente a isso e também ao culto dos deuses ctônicos, a sibila apareceu como purificadora e expiadora, segundo Rossi (1915a, p. 209).

\section{Entre a sibila pagã e a sibila cristã}

Não é tarefa simples deslindar o caminho percorrido entre a sibila pagã e sua incorporação pelo cristianismo. Não existe um fato único, ou momento histórico exclusivo que responda com suficiência a esta questão, mas, ao contrário, diferentes ocasiões e eventos se interpõem e concorrem para a sua elucidação. Trata-se por isso de uma sobrevivência efetiva. A questão divinatória e profética é um elemento comum e peculiar ao complexo quadro de relacionamentos difíceis (mas forçosos) da nova mensagem religiosa cristã com o panorama multiforme (mas essencialmente homogêneo) das civilizações que afluíam dentro do império romano. Tanto da parte da cultura pagã, como da judaica e da cristã, houve uma sede insaciável de conhecimento do futuro, misto de esperança e temor. Esse foi 
um ponto crucial na tessitura da afirmação religiosa dessas distintas cultuas e na busca, seja de sua afirmação religiosa, como de suas peculiaridades(Gasparro 1999, p. 505-553). A partir desses pressupostos, já se torna possível distanciar o espanto e a admiração com relação à presença maciça das sibilas também no mundo cristão.

Dentre os diferentes momentos históricos nos quais as questões proféticas e divinatórias surgem e ressurgem com fervor, não é incomum que compareçam diferentes estirpes de profetas e adivinhadores, com maior ou menor sucesso (dentre os quais as sibilas têm um lugar privilegiado) ao lado da astrologia com a sua prática divinatória do zodíaco. Quanto a esta última, é legítimo pensar que efetivamente a astrologia não saiu completamente de cena com a chegada do cristianismo. Pode-se compreender que de uma forma ou de outra, os astros estavam ainda presentes no mundo cristão. Assim, por exemplo, o Apocalipse de João, que tem grande parte de suas imagens mais eficazes no misticismo astral, promete ao fiel vitorioso o domínio dos povos até à morte, mas também o domínio sobre a estrela matutina, como mostram Franz Boll e Carl Bezold (2011, p. 45).

Mas, se de um lado os versos apocalípticos falam frequente e claramente da vitalidade intemerata da fé nas estrelas, por outro lado não faltam exemplos de sua reprovação. Lembre-se, a esse título, a Carta aos Romanos de São Paulo (8,38-39) na qual ele celebra o triunfo do amor de Deus sobre todos os poderes astrais e do destino. Mais tarde, ainda segundo Boll e Bezold (2011, p. 45) também os apologistas cristãos afirmarão que é tolo e sacrílego adorar a obra de Deus - o universo - elevando à divindade o sol, a lua, os astros, em vez de adorar o Deus mesmo. Entretanto, no momento no qual a comunidade cristã procurou se abrir à cultura laica, foi inevitável que a crença nos astros se lhe apresentasse como um dos elementos essenciais não facilmente extirpáveis de tal cultura, conforme se confirma em Firmico Materno (Mathesis, 1, 10, 14; 5, praef. 3), escritor e astrólogo romano do século IV. Assim, não é de se espantar que a persistência da influência da religião astral apareça, por exemplo, quando a Igreja, em meados do século IV, de certa maneira substituísse Cristo pelo Deus Sol, enquanto Sol da Justiça, 
mudando a data do seu nascimento para 25 de dezembro, isto é, para o dia que, para os pagãos, significava o aniversário do sol. Isso quer dizer que daí em diante o dia se ampliava e um novo sol iniciava o seu ciclo anual. A fórmula Lux crescit já existente no calendário grego e na liturgia pagã, foi introduzida literalmente na prédica cristã do Natal, segundo Eduard Norden (1924, p. 101). Também o dies Solis, isto é, o domingo, que a Idade Média Ocidental herdou da semana planetária dos astrólogos, transformou-se no dia do Senhor, estabelecido acima do shabbat dos judeus, evocando sentimentos de bem-aventurança em milhões de crentes que por vezes desconheciam a origem pagã do vocábulo. Os próprios evangelhos ligando o milagre do eclipse solar à morte de Cristo, e também contando a lenda dos Reis Magos que viram uma estrela no Oriente a partir da qual foram guiados a Belém, acabaram por colocar em estreita relação a astrologia com a vida de Jesus como nos informam Boll e Bezold (2011, p. 47).

De maneira mais profunda, Warburg - autor que aqui nos é muito caro por tematizar a sobrevivência do mito antigo - ao falar da história da persistência da tradição antiga, aborda de forma especial a astrologia e os símbolos do zodíaco. Poder-se-ia dizer que sua ideia de fundo a este respeito é que a astrologia é parte dos esforços do homem ao longo dos séculos, para se orientar no mundo. Partindo das pinturas alegóricas de Botticelli, no renascimento, ele chega à história do símbolo astrológico. O nascimento e a persistência da astrologia são compreendidos, em consonância com as afirmações de Ghelardi (2011, p. XVI), como uma necessidade psíquica consubstancial ao homem que oscila entre a atitude religiosa e a científica. No conhecimento do céu, encontramos a questão humana mais ampla de orientação espiritual em face do universo.

Para Warburg (2013, p. 447-448) os antigos deuses não estão mortos ainda. Se hoje sabemos que as divindades pagãs sobreviveram e que a ideia de um renascimento do antigo pantheon nos séculos XV e XVI depois de um longo ofuscamento é falsa, devemos isso a Warburg e aos warburguianos. Dentre eles, Jean Seznec em seu ensaio sobre A Sobrevivência dos Antigos Deuses, mostra, ressaltado no prefácio de Salvatore Settis (2015, p. VII-XXIX) que na cultura 
ocidental um relacionamento absolutamente peculiar liga a tradição judaico cristã às imagens dos deuses do Olimpo e das origens míticas da astrologia. Apesar de se distanciar em alguns momentos das assertivas de Warburg, Seznec compartilha com este a sustentação do argumento que recusa considerar o renascimento como uma ruptura radical com o passado, ou como um início literal. Entende-se aqui uma negação da morte dos deuses pagãos durante o medievo, para afirmar uma sua metamorfose. Em contraste com convenções de sua época, Seznec consegue mostrar, a partir do conceito de metamorfose, como os deuses medievais - "esses deuses fantasmáticos e abastardados tão teimosamente incompreendidos" (SEZNEC, 2015, p. 173, tradução nossa) ${ }^{1}$ - continuaram a viver através dos séculos e nos países mais diversos. A sobrevivência das sibilas também se faz notar ao longo da história e sua presença ao lado do zodíaco como linguagem oracular surge em distintos momentos desde a antiguidade.

Tendo afastado o primeiro espanto com relação à presença das profetisas pagãs no mundo cristão, proponho voltarmos a atenção, de maneira acurada, para alguns períodos em especial da história cristã em cuja contextura da malha societária e visão de mundo encontram-se elementos esclarecedores para a nossa questão, qual seja a da sobrevivência das sibilas no catolicismo. Não só o ambiente literário será aqui afrontado, mas também, em linhas gerais, as representações plásticas das sibilas a ele correlatas.

\section{Do cristianismo primitivo à institucionalização da igreja}

O primeiro momento, sem dúvida determinante, é o dos padres apologistas no cristianismo primitivo e da patrística até à institucionalização da Igreja Católica, (com o I Concílio de Niceia, convocado pelo imperador Constantino) ressaltando Lactâncio e Santo Agostinho. O primeiro imperador cristão, na sua mensagem para este concílio, realizado no ano de 325, interpretou a passagem das Écoglas ou Bucólicas de Virgílio como uma referência à vinda de Cristo. Constantino assim apresenta a Sibila:

\footnotetext{
${ }^{1}$ Versão original italiana: "questi dei fantomatici e imbastarditi che vengono così caparbiamente misconosciuti".
} 
Eu mencionei várias provas da divindade de Cristo. A Sibila Eritreia, a qual afirma ter nascido na sexta geração depois do Dilúvio, era sacerdotisa de Apolo. Portando a guirlanda como o deus que ela venerava, e administrando o tripé entorno do qual está enredada a serpente, ela lançava oráculos apolíneos àqueles que lhe suplicavam, pela loucura dos seus pais que a tinham consagrado a esse mister, através do qual emergem paixões inconvenientes e nada de solene, como se vê na lenda de Dafne. Ela, entretanto, dentro do adyton, arrastada por esta superstição absurda, e estando cheia de inspiração genuinamente divina, profetizou em versos o que teria acontecido com relação a Deus e de maneira clara, com as letras iniciais dos versos, que são claramente um acróstico, revelou a história da vinda de Jesus. (CONSTANTINO apud PARKE, 1992, p. 201).

Constantino prossegue citando por inteiro os 33 versos dos Oracula Sibyllina (dos quais falaremos a seguir), livro oitavo, que trata do dia do Juízo, com um acróstico formado pelas iniciais dos versos nos quais se leem: Jesus Cristo, Filho de Deus, o Salvador. O imperador aponta, então, como exemplo da profecia da Encarnação, a quarta Écloga de Virgílio, verso quatro, (composta no ano 40 a.C.), que expõe em detalhes, fundamentando-a no oráculo da sibila, como afirma Parke (1992, p. 201-202). Virgílio aborda a sibila também no livro VI de Eneida, mas não relacionada com a previsão do nascimento de Cristo. A interpretação da Écloga ou Bucólica está alinhada à tradição mitopoética na qual as Éclogas IV e VI estão relacionadas à iniciação dos mistérios, de acordo com Maury (1944, p. 71147). Como exemplo disso, na interpretação de Eduard Norden (1945, in SOUZA, 2006, p. 67) da quarta Bucólica, esta aparece como um hino à natividade, à glorificação do nascimento do Menino compreendido como a gênese de uma nova humanidade.

Sob este aspecto, o das permanências de determinados elementos antigos em distintas culturas e diferentes momentos históricos, pode-se pensar que a sibila é uma figura que nunca perdeu sua força ritual de matriz pagã. Nos seus gestos, ou mesmo na sua voz, ela sempre procurou comover e era sempre plena de pathos. Na apropriação e reinterpretação cristã dos séculos IV e V, a sibila parece nunca ter perdido os seus traços inegavelmente antigos: virgem, sábia, visionária e consciente do seu poder necromântico que lhe permitia acessar o mundo além-túmulo. Seja na sua aparência, seja na sua iconografia, a sibila nunca deixou de ser pagã, portando do mundo antigo o caráter patético e emocional dos profetas. 
Se Constantino foi um marco, cabe lembrar que antes dele as sibilas vinham sendo já citadas pelos padres da Igreja. Depois que Virgílio mencionou a sibila, esta se tornou uma figura comum na literatura latina. Os cristãos viram então, nesta Bucólica, segundo Brown (2007, p. 78), a profecia do nascimento virginal do Messias que tirou o pecado original. É nesse ambiente deliberadamente literário, antes mesmo da citação de Constantino, que a sibila aparece nos escritos dos Padres da Igreja. De acordo com Parke (1992, p. 181-183) Erma, irmão do papa Pio I (santo, décimo papa da Igreja Católica Apostólica Romana, entre os anos 140 e 154) e autor do célebre escrito $O$ Pastor (obra cuja primeira parte consta de uma série de visões nas quais o autor recebia diversas instruções morais e espirituais), relata o encontro com uma sibila, uma velha senhora com um livro nas mãos. Ainda segundo Parke (1992, 185-186), há uma parte dos Padres da Igreja em cujas obras as sibilas vêm citadas como fontes de ensinamentos evangélicos e espirituais. No mesmo período, como nos informa Momigliano (1987, p. 408-409), São Justino, mártir e escritor cristão, na sua Apologia (152-153 c.) cita a sibila como tendo previsto a destruição pelo fogo, daquilo que havia sido criado. A destruição do mundo pelo fogo está já no Livro Terceiro dos Oracula Sibyllina. Sobre esta coletânea anônima dos oráculos das sibilas, a erudição greco-romana estava convencida de que circulasse antes da Guerra de Troia e que Homero houvesse sabido o futuro dos descendentes de Enéas por meio dos ditos oráculos. Entretanto, a primeira menção a um oráculo sibilino, na literatura grega, conforme Parke (1992, p. 11), é feita por Heráclito, no fragmento 92, e não pode ter sido muito anterior ao ano 500 a. C. A forma atualmente existente dos Oracula Sibyllina, ainda em consonância com esse autor, foi recolhida de um anônimo historiador bizantino do século VI d. C. São doze livros que apresentam uma mistura das formas gentílica, judaica e cristã, datados do período entre 140 a.C. e o século III d.C. Esses 12 livros restantes de 14 originais são numerados de um a oito e de 11 a 14. Os livros nove e 10 se perderam e o sete encontra-se muito danificado. Os escritores de apologias cristãs, posteriores a São Justino, citavam ocasionalmente os Oracula Sibyllina. Outro autor cristão fez um uso mais amplo dos oráculos sibilinos: Lactâncio $\left(3^{\mathrm{O}}-4^{\mathrm{O}}\right.$ século), nas suas Instituições Divinas, uma obra de poderosa apologética cristã, escrita em latim e dividida em sete livros. 
Nelas o autor mostra o conhecimento dos oráculos sibilinos, ao menos dos de número três a oito e lhes faz referência, sem, no entanto, fazer longas citações. Está claro, portanto, que Virgílio não foi a única fonte de inspiração para a presença das sibilas nos escritos da Patrística. Mais do que quaisquer outros Padres da Igreja, Lactâncio dedicou tempo e atenção de erudito, na tentativa de por as sibilas no contexto histórico em que vivia e extrair das suas mensagens o máximo de instrução religiosa.

O triunfo do cristianismo demandaria ainda um século para ser levado a cabo, mas a teologia já voltava a atenção ao problema da formulação de um credo detalhado e à necessidade de fazer frente àqueles que colocavam objeções às regras e às crenças de uma igreja constituída. Não é, pois, por acaso que aquela importante declaração sobre a sibila tenha vindo do primeiro imperador cristão. Erma, o primeiro padre a citar as sibilas, ainda que vivesse em Roma, o fez em grego. Ao fim do século IV, no entanto, o latim era a língua dominante do Império do Ocidente. Isso causou um arrefecimento na circulação dos textos originais gregos dos Oracula Sibyllina. Não eram mais inteligíveis para as classes baixas e perderam importância junto aos eruditos. Agostinho é um exemplo disto, e pode-se confirmar pelas informações de Parke (1992, p.200-201). Tendo lido poucos autores gregos, tinha conhecimento limitado dos oráculos sibilinos, como ele próprio afirma na Cidade de Deus: "Eu mesmo tive gosto de ler alguns versos, em mau latim e rima ainda pior, devidos a tradutor desconhecido, segundo pude comprovar mais tarde" (AGOSTINHO, cidade de Deus, XXIII, 1). O bispo de Hipona informa que o procônsul de África Flaciano, ter-lhe-ia apresentado um acróstico grego como sendo profecia da sibila Eritrea, cujo sentido seria o seguinte:

A terra cobrir-se-á de suor frio. Será o Juízo final. O Rei imortal dos séculos baixará do céu e apresentar-se-á em carne para julgar a terra. E, quando o mundo decline para o seu ocaso, o fiel e o infiel verão Deus, acompanhado de seus santos. As almas apresentar-se-ão ao juiz com os respectivos corpos e na terra já não haverá beleza nem verdura. Os homens deixarão os ídolos e as riquezas [...]. Então, revelando os seus atos ocultos, cada qual descobrirá os próprios segredos e Deus fará luz nos corações [...]. (AGOSTINHO, 2013, XXIII, 1). 
Antes de ter acesso a este acróstico, no entanto, a Sibila para Agostinho tivera um papel menor e não necessariamente positivo. Por exemplo, no tratado Contra Fausto a sibila é posta entre Orfeu, Hermes Trismegisto e outros profetas ou pregadores e sábios que teriam predito ou dito a verdade sobre o Filho de Deus e sobre Deus Pai. Ainda que o autor lhes atribua por isso algum mérito, afirma que, no entanto, teriam ensinado aos gentios que os ídolos e os demônios deveriam ser venerados (AGOSTINHO, 12.15). O veredito final sobre a Sibila, dado na Cidade de Deus, possibilitou ao ocidente alinhavar as suas próprias lendas das sibilas por toda a Idade Média:

[...] o referido poema da sibila Eritreia ou, como outros preferem Cumeia, em sua composição não contém nada que favoreça o culto aos deuses falsos; ao contrário, tão acremente fala contra eles e seus adoradores, que me parece poder ser enumerada entre os pertencentes à cidade de Deus. (AGOSTINHO, 2013, XXIII, 2.).

Ainda que Santo Agostinho tenha legitimado as sibilas e suas profecias, não fez o mesmo com relação à astrologia, condenando-a vivamente como irracional e supersticiosa, como afirma Minois (2007, p 140-141).

É importante ressaltar que, se autores como Rossi (1915a, p. 209) e Peretti (1943, 26-31) nos informam que a primeira sibila de que se tem registro é proveniente da Babilônia, não se pode, no entanto, negar que foi da Itália meridional que o sibilismo irradiou para a França, Alemanha e para o restante da Europa. A este primeiro período abordado corresponde uma única representação da sibila, uma mulher no arco triunfal dos mosaicos paleocristãos da Igreja de Santa Maria Maggiore em Roma (432-443). Castiñeiras (2016, p. 110) aponta três autores que identificam a mencionada figura feminina a uma sibila. 


\section{Figura 1 - Mosaicos do arco triunfal da basílica papal de Santa Maria Maior (Santa Maria Maggiori), em Roma}

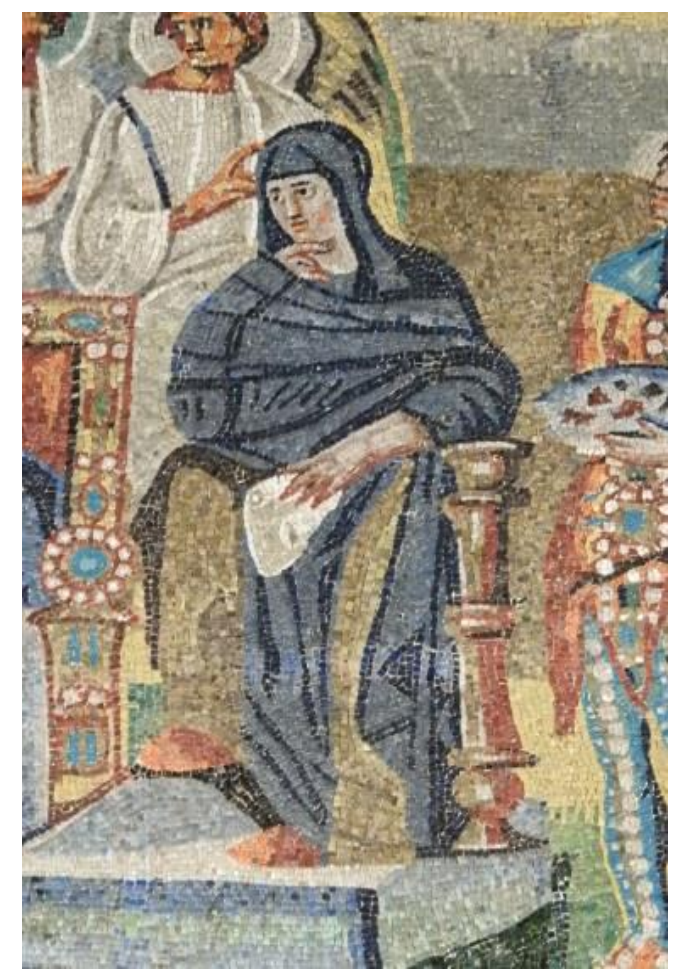

Fonte: Fotografia da autora.

\section{A Igreja medieval}

A Igreja medieval, e é este o segundo momento ao qual nos dedicamos, tenta disciplinar o futuro ou a sua predição entre o estabelecimento do que seria profecia ortodoxa e profecia herética. Desde os primórdios do cristianismo - uma religião essencialmente profética na qual a profecia é uma "gracia grátis data" (PARERA, 1999, P. 176) - a Igreja lutara contra uma quantidade imensa de consideradas superstições herdadas da era precedente, tentando estabelecer, no que concerne às profecias, o que era de inspiração divina e o que não era. Era profícua a presença de sonhos, visões, profecias. Necessário se fazia ao mesmo tempo desencadear a predisposição própria das pessoas às previsões e ao mesmo tempo disciplinar e canalizar as inspirações proféticas para que não se tornassem uma ameaça ao cristianismo. Exemplo disso, na alta Idade Média, Gregório Magno, por volta do ano 600 escreveu uma obra rica em alegorias, dando prova de crer nos dons 
proféticos. De acordo com Lerner (1976, p. 7) numa época em que as fronteiras entre o natural e o miraculoso, o presente e o futuro se atenuavam até mesmo nas mentes de uma elite cultural, não é de se espantar que tenha havido um recrudescimento das consultas aos adivinhos, astrólogos, videntes, profetas, e todos aqueles intermediários que têm acesso ao futuro. Dentre eles, as sibilas estão presentes.

Uma parte considerável das profecias religiosas medievais se deve a uma efetiva insatisfação com o presente e uma insegurança e desesperança com relação ao futuro. Conforme Rossi (1915a, p. 218) no século XI, uma desordem das almas criou insatisfação e desequilíbrio a partir das mudanças como a retomada do comércio, o desenvolvimento das cidades e a aparição da burguesia, juntamente com o surgimento de bandos de mercenários e mendicantes. Na mesma época há um ressurgimento de um clima apocalíptico. Este século viu a luta entre a Igreja e o Império Germânico. Foi um século no qual o mundo cristão foi tomado várias vezes pelo medo apocalíptico que preparava os povos para a iminência de uma luta final, como afirma Minois (2001, p. 166). O clima apocalíptico e o medo diante das desordens advindas das rápidas mudanças no mundo tradicional trouxeram fortemente o desejo de conhecimento do futuro. Houve um retorno importante da astrologia e das profecias sibilinas que são, ao mesmo tempo, concorrentes e complementares aos profetas do Antigo Testamento. Segundo a mesma autora, é do século XI a primeira representação da sibila no universo medieval. Uma pintura parietal, na Basílica de Sant'Angelo in Formis, dos frades beneditinos, representa a sibila já honrada na Igreja, lado a lado com os doze profetas de Cristo. A sibila em questão não está nomeada, mas encontra-se nas terras onde tiveram longa duração a tradição das sibilas Cumana e Ciméria, sendo provavelmente esta uma das profetisas comparecentes na tradição regional. Rossi (1915a, p. 217) nos recorda que São Bento, além de fazer também suas profecias, é protagonista de uma lenda, segundo a qual teria tido um encontro com a sibila. 


\section{Figura 2 - Sibila de Sant'Angelo in Formis, Basílica Beneditina de Cápua}

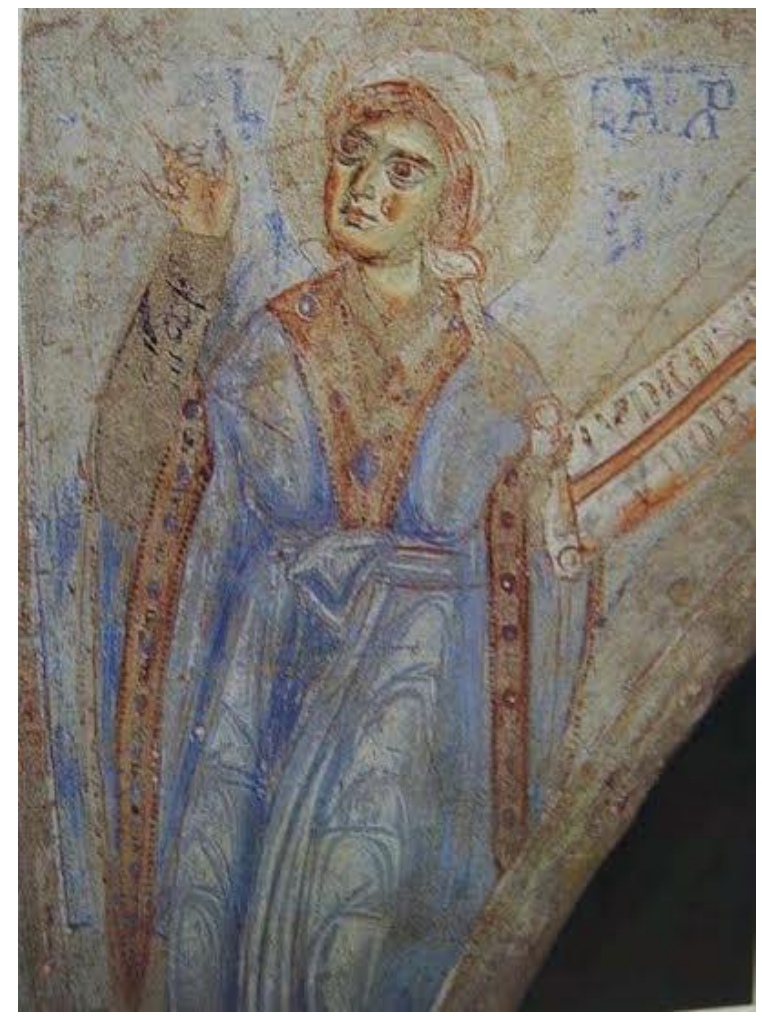

Fonte: Fotografia da autora.

Neste ponto, torna-se extremamente importante a compreensão da sobrevivência e incorporação da astrologia em sua vinculação com as sibilas, como testemunhos "de fora" do cristianismo. Em meio à indefinição entre as categorias naturais e sobrenaturais, que pode ser notada nos testemunhos gentios para as verdades cristãs, tomava grande importância os depoimentos não cristãos pronunciando a doutrina cristã. Abordamos já a quarta écloga de Virgílio que aqui se encaixa como testemunho gentio. Para tanto é também retomado o apóstolo Paulo para legitimar e valorizar os testemunhos de fora, mormente astrólogos e sibilas: "Também deve ter boa reputação perante os de fora, para que não caia em descrédito nem na cilada do diabo" (SÃO PAULO, Carta a Timóteo, 3:7). Os leitores medievais estavam já familiarizados com as origens antigas da astrologia, através das Antiguidades Judaicas, de Flavio Josefo, por meio do seu texto traduzido para 
o latim no século VI e também através de seus leitores posteriores, como afirma Smoller (2010, p.79). Josefo, segundo esse autor, remonta a arte da astrologia ao tempo dos patriarcas, por exemplo, atribuindo a longevidade de Noé a um profundo conhecimento de geometria e astrologia e o conhecimento das estrelas também a Abraão. Por meio dessas fontes a noção de que a astrologia era uma arte antiga e revelada, praticada pelos patriarcas, passou para a corrente principal da tradição cristã.

Nesse cenário houve uma onda de traduções de textos de astrologia do universo árabe e composição subsequente de novas obras astrológicas latinas. De destacada importância, segundo Sadan (2000, p.15) foram as obras do teólogo Albumasar, nascido no século VIII, também matemático, astrônomo, astrólogo e filósofo persa, que escreveu uma série de manuais práticos sobre astrologia de profunda influência na história intelectual muçulmana e, através das traduções, também na elaboração da astrologia medieval. De acordo com Smoller (2010, p. 80) Hermann de Carinthia, tradutor de Albumasar, incorporou em sua obra De Essentiis o nascimento da Virgem como posta no Introductorium Maius do autor muçulmano e vestígios da sua história das origens e dos progressos da astrologia. $\mathrm{O}$ uso dos textos de Albumasar por Hermann serviu tanto para defender a validade da astrologia quanto para reforçar a fé cristã. No De Essentiis, Hermann também justapõe astrologia com a profecia sibilina como dois precursores do advento de Cristo. Hermann teria sido o primeiro apologista cristão a utilizar o fragmento de Albumasar associando-o à Virgem Maria. Trata-se de uma farta legitimação da verdade cristã por meio dos profetas "de fora". Sibilas e astrologia aparecem juntas novamente como testemunhos de fora em um sermão sobre a natividade da Virgem pregado por Garnier de Rochefort, abade de Claraval, no final do século XII. No referido sermão, o abade de Claraval faz numerosas alegações eruditas que ilustram de forma premonitória a maternidade virginal de Maria. Segundo Avilés (s/d, p.189-200) o abade cita para tanto Albumasar, evocando a figura da constelação zodiacal de Virgem como prefiguração pagã da Virgem Maria. 
Albumasar associa o signo de Virgem à Virgem Maria e ao menino Jesus, bem como à previsão de seu nascimento na associação com a sibila Química, retomada no século XV por Filippo Barbieri, que mais abaixo será abordado. A legenda abaixo da sibila Química da obra de Barbieri remete à previsão de Albumasar do nascimento virginal de Cristo, como mostra Smoller (2010, p. 76). Assim a astrologia dos antigos revelou que a autoridade das sibilas está em pé de igualdade com a ciência das estrelas. No poema intitulado De Vetula (que fora falsamente atribuído a Ovídeo, mas que, segundo F. Bottin (1990, p. 85) pode ser considerado de autoria de Ricardo de Fournival que viveu entre 1246 e 1260) astrologia e sibila operam em conjunto na previsão de uma mudança religiosa. Também Roger Bacon, filósofo do mesmo século que era conhecido como doutor admirável pela sua ênfase no empirismo e no uso da matemática, era um ávido leitor do De Vetula. Na parte IV do seu Opus Maius de 1266, dirigida ao Papa Clemente IV, Bacon, seguindo Albumasar e o De Vetula mostra que o nascimento de Cristo tinha sido previsto nas estrelas. Ele tenta convencer o papa de que, juntamente com outras ciências, as profecias da Sibila, de Merlin, de Joaquim de Fiore e de tantos outros, poderiam dar uma maior segurança no tempo do Anticristo. Na sua crença nas origens reveladas de todas as ciências, ele esfumaça a linha divisória entre astrologia e profecia. É digno de nota o fato de que, no século XIII, ninguém menos que Tomás de Aquino (Suma Teológica : $2^{\text {a }}$ PARTE, II SESSÃO, QUESTÃO 172, ARTIGO 5 E 6), o grande doutor da escolástica tenha também mencionado as sibilas, corroborando as palavras de Santo Agostinho e confirmando que suas profecias seriam de inspiração divina e não demoníaca. É também de grande importância neste contexto, a obra do mestre do doutor de Aquino, Alberto Magno. O seu tratado Speculum Astronomiae seria responsável pelo elogio definitivo que consolidou a fama de Albumasar como profeta do nascimento de Cristo na baixa Idade Média, já abordado por Bezold (citado por Avilés, 1992-1993, p.196) nos finais do século XIII. Ali ele oferece uma classificação dos livros lícitos e ilícitos de astrologia e magia, no qual legitima a obra de Albumasar, além de estabelecer uma relação entre o nascimento de Cristo e o horóscopo de Cristo, o que explica também como essas duas cenas se fundiram em uma só imagem aos olhos dos ilustradores. Estava, então, solidificada a relação 
entre a constelação zodiacal de Virgem e a Virgem Maria, que teve grande sucesso na Idade Média. São também numerosas as representações do zodíaco nas igrejas católicas desde a Idade Média, como nos mostram Fritz Saxl (2016, p. 47- 287) e Erwin Panofsky (2016, p.9-135).

\section{Figura 3 - Relógio com zodíaco: Igreja de Santa Maria dei Servi, Pádua, século XV}

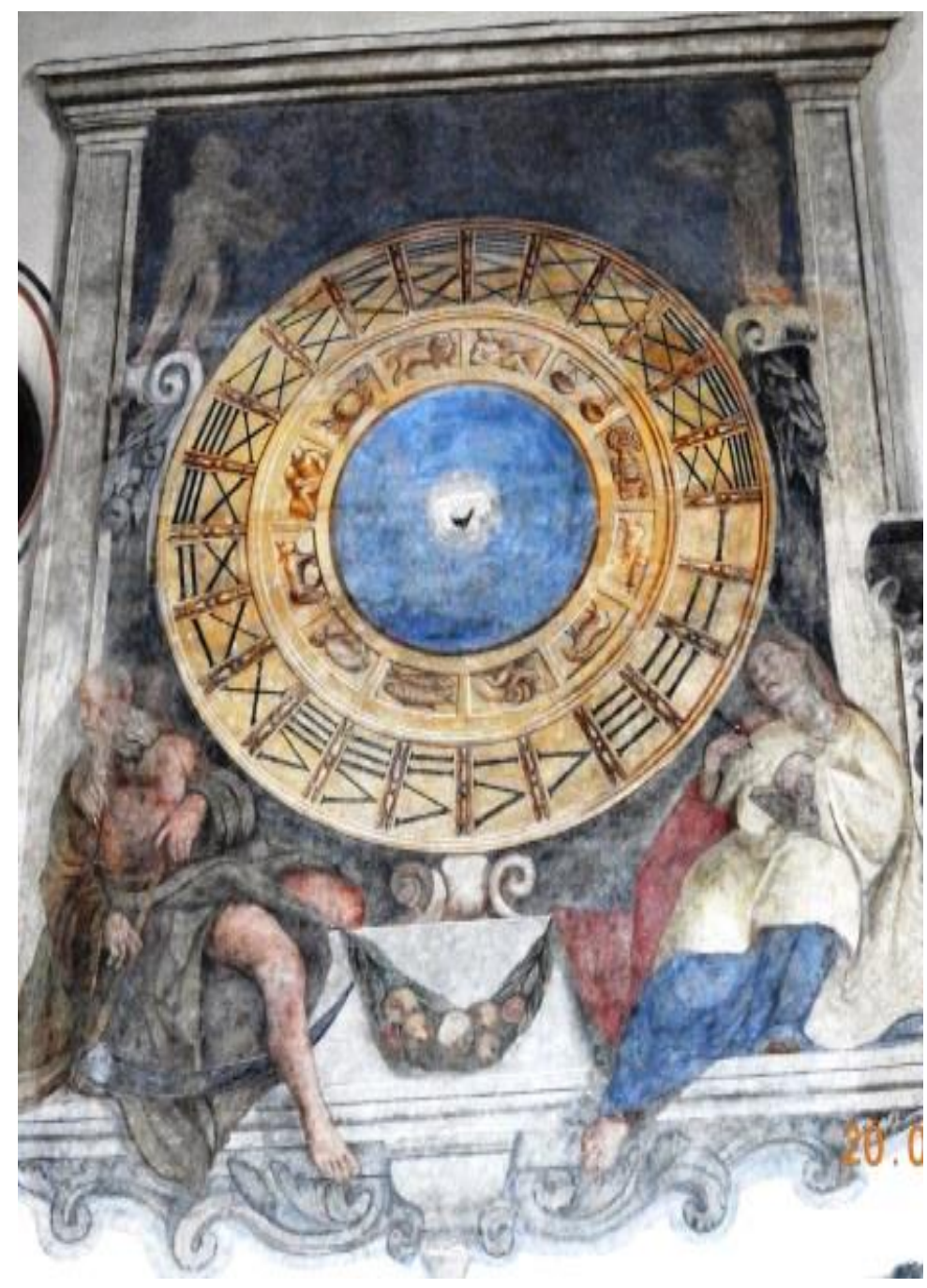

Fonte: Fotografia da autora. 
Do século XIII existem importantes representações das sibilas na Itália. Destacam-se duas esculturas em Ravello e de Sesso Aurunca, ambas na costa Amalfitana, tidas como as primeiras representações das sibilas em mármore. Foi um novo momento de apelo ao sibilismo, especialmente no sul da Itália, onde foi grande a influência das ideias do já mencionado abade Joaquim de Fiore. Igualmente do século XIII é pintada em Roma, na Igreja de Santa Maria in Aracoeli uma sibila, pelas mãos do pintor Pietro Cavallini. Essa pintura, que narrava a lenda da sibila Tiburtina e do Imperador Augusto foi destruída e substituída por outra do século XVI, feira por Nicolò Maerinelli, dito o Trometta.

\section{Renascimento}

No século XIV, de acordo com Smoller (2010, p. 83) a começar com Arnaldo de Villa Nova na sua obra Antichristo um grande número de estudiosos colocou-se contra Roger Bacon e sua astrologia do apocalipse. No entanto, isso não foi suficiente para anular a tendência de emparelhar astrólogos e sibilas como testemunhos da encarnação. Este emparelhamento aparece com destaque na obra de João de Paris, um dos vários autores que escreveram em resposta a Arnaldo. Em João de Paris aparecem mais uma vez sibilas e astrologia em pé de igualdade. Ainda neste século, João de Legnano, de Bolonha, mais conhecido por suas obras como jurista, apresenta a astrologia e as sibilas em pé de igualdade. Esse autor tinha também um grande interesse por astrologia e teologia, temas que aparecem em seu Advento Christi de 1375, presenteado ao Papa Gregório XI. Depois de Legnano, oráculos sibilinos continuaram a se misturar com material astrológico e a aparecer em paralelo com as profecias do antigo testamento na arte e nas letras. Em algum momento daquela década o Cardeal Orsini pintou em seu palácio em Roma as 12 sibilas com os textos que haviam previsto a respeito de Cristo. No Palácio de Orsini as previsões de Albumasar agora serviam para descrever a sibila Química que por sua vez profetizou o nascimento de Cristo. A pintura desapareceu, mas inspirou as gravuras de Baccio Baldini no século seguinte, segundo Dempsey (2006, p. 85-98). Do século XIV importantes figurações de sibilas em igrejas 
devem ser notadas, para além das iluminuras igualmente numerosas. Uma ocorrência exemplar é a escultura de Giovanni Pisano no púlpito da Igreja de Santo Andrea, em Pistoia, onde seis sibilas anunciam a paixão em meio às virtudes.

A totalização de 12 sibilas, presente já no palácio Orsini, nas gravuras de Baccio Baldini e na obra do dominicano Filippo Barbieri, teólogo, filósofo, historiador e inquisidor, corroboram numericamente a relação com os signos do zodíaco e com os profetas veterotestamentários. Apesar de ser voz corrente que Fillipo Barbieri teria acrescentado duas sibilas à lista de Varrão (que viveu entre 116 e 27 a. C. e estabeleceu o número de 10 sibilas), percebe-se que era já um dado da cultura a existência das 12 profetisas. A importância hoje reverberada da publicação de Barbieri deve-se em grande medida a uma notável obra que apareceu na França do século XIX. Nos estudos de Émile Mâle Quomodo Sibyllas recentiores artifices repraesentaverint, a tese latina sobre as sibilas, discutida na Sorbone em 1898, o autor mostra como Barbieri tem efetivamente uma grande importância como base iconográfica das representações das sibilas nas igrejas a partir de então, uma vez que estabelece características físicas, vestimentas, idade e atributos específicos a cada uma delas em sua obra Discordantiae sanctorum doctorum Hieronymi et Augustini, publicada pela primeira vez em 1481 e por diversas vezes reeditada². Mâle afirma que antes de Barbieri, na Idade Média, as sibilas representadas em França e Itália eram somente duas: Eritreia e Tiburtina, respectivamente. Em obra de 1912 L'Art religieux du XIIIe siècle en France, este autor afirma que a sibila, ainda que representante do paganismo, podia anunciar o Salvador. A partir dessas considerações, vemos como, ao longo da tese latina, a sibila, uma figura antiga que traz uma palavra reveladora, assume as características de uma imagem "explicativa". Como afirma Giustiniani (2013, P. 125) a sua obra é grandemente reverberada e ele mostra como, com uma referência a Vincent de Beuvais em seu Speculum Mundi (que por sua vez remete à Lactâncio), a Idade Média até o século XIII admitia a existência de 10 sibilas. Ele entendia as representações das figuras pagãs como uma expressão da antiguidade perdida. No

\footnotetext{
${ }^{2}$ Há, na Biblioteca Apostólica Vaticana (2018), uma edição disponível.
} 
Prefácio à La Sopravvivenza degli Antichi Dei, obra já citada de Jean Seznec (2015, p. 07), este último deixa claro que Émile Mâle foi um inspirador, encorajador e facilitador do seu trabalho. É, portanto, um autor que, em distinta seara se alinha a Warburg no sentido de mostrar como os antigos deuses sobreviveram mesmo na Idade Média. A sibilia “[...] é a voz do velho mundo. Toda a antiguidade fala pela sua boca", afirma Mâle (1902, p. 379 apud GIUSTINIANI, 2013). Quando se pensa na representação das sibilas em relação ao zodíaco, é oportuno recordar que, segundo Rossi (1915b, p. 280), as sibilas esculpidas por Giovanni Pisano teriam inspirado as esculturas de Agostino di Duccio, um século e meio mais tarde, nas 10 sibilas do Templo Malatestiano de Rimini. Ainda que aqui não tenhamos o número de 12, as profetisas estão acompanhadas de dois profetas, totalizando a dúzia. E no mesmo templo, Duccio representou os símbolos do Zodíaco. As esculturas de Duccio no Templo Malatestiano foram abordadas por Warburg (2008, 89-93) que mostrou como, sendo quase maneiristas na sua figuração, fazem "empréstimos" de obras de arte antiga.

Em outro local, na chamada "sala das sibilas" ou apartamento Borgia, no Vaticano, estão representadas, no teto, 12 sibilas alternando em pares com os profetas, enquanto nos painéis octogonais aparecem os símbolos do zodíaco. Ainda uma vez ali, a sibila Cimeria ou Química, tem um pano com palavras que remetem a Albumasar. Fritz Saxl em 1957 escreveu The Appartamento Borgia, pelo Instituto Warburg, traduzido por Eugenio Garin e publicado na Itália, pela primeira vez, em 1982, como um capítulo do livro La Storia delle Immagini. Ali ele faz uma importante análise do ponto de vista da história social da arte, que não fora ainda feita. 
Figura 3 - Osea e Délfica. Pinturicchio, Apartemento Borgia, Musei Vaticani

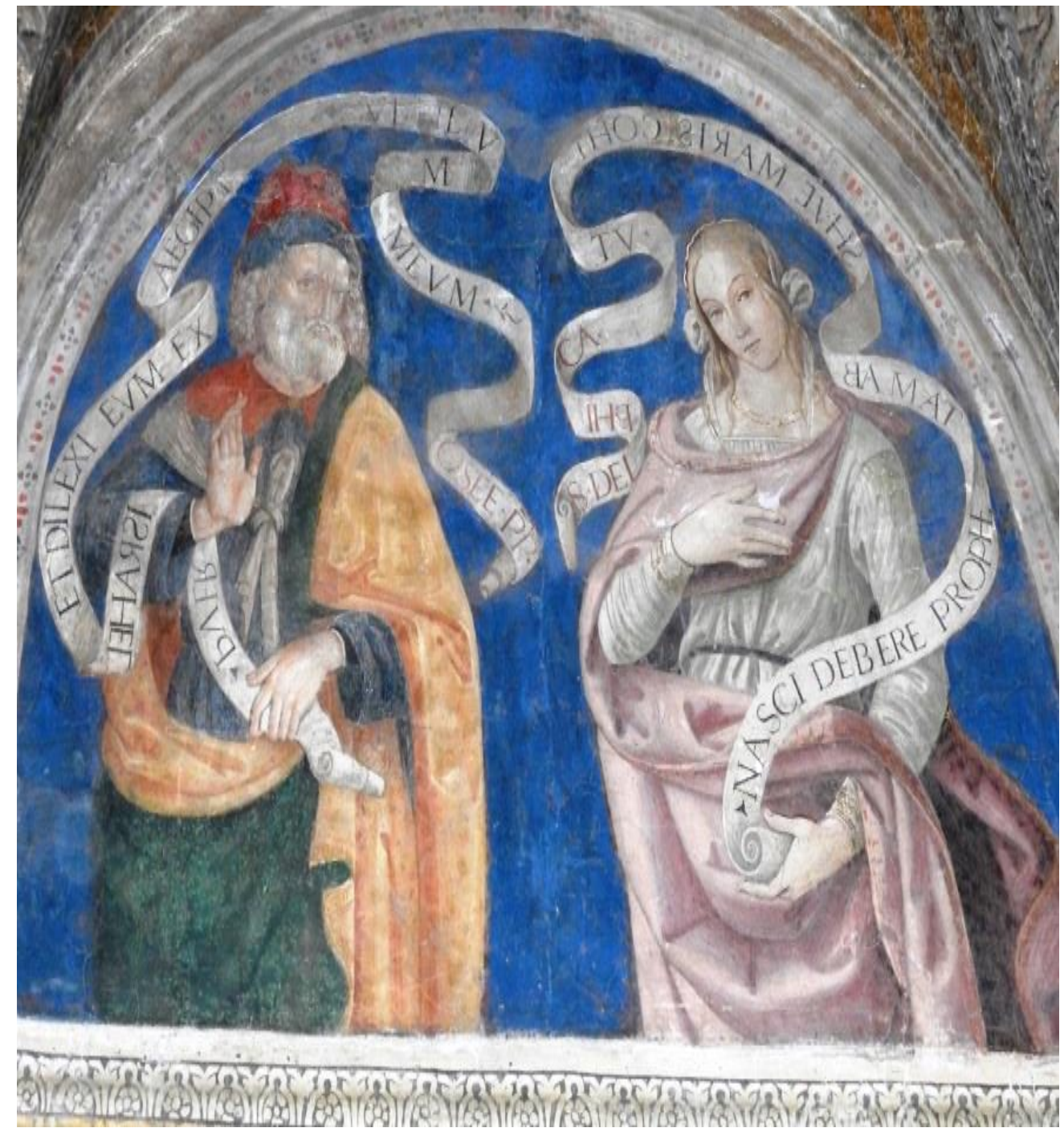

Fonte: Fotografia da autora.

Do século XV são ainda de grande relevância as sibilas esculpidas em bronze dourado por Ghibert na porta leste do batistério de Florença, entre 1425 e 1452. A porta original, hoje restaurada, encontra-se em exposição no Museu do Duomo em Florença. 
O renascimento é, na verdade o momento no qual se veem cada vez mais profecias extrabíblicas e astrologia ocupando o mesmo território, frequentemente dentro de uma estrutura escatológica e legitimando o cristianismo. Não é por acaso que é neste momento, do século XV em diante, que se tem o maior número de representações das profetisas nas igrejas. Novamente aqui a junção entre astrologia e sibilas se dá, seja na literatura, seja nas representações plásticas. Podemos citar um exemplo, do final do século XV, como validação tanto das sibilas quanto de material astrológico como fontes de conhecimento religioso verdadeiro: no pavimento da Catedral de Siena, em representação marmórea monumental, estão Hermes Trismegisto e as dez sibilas.

O filósofo do século XV Marsílio Ficino afirma igualmente que a astrologia foi mais uma forma pela qual os gentios chegaram aos mistérios cristãos. Dentro do seu sermão De Stella Magorum a estrela leva os magos ao menino Jesus não apenas pelo seu brilho e movimento, mas porque eles sabiam interpretar a posição dos astros em torno da estrela. Nessa obra ele cita as as palavras de Albumasar sobre a imagem da donzela na primeira face de Virgem, que remete à Maria como nos informa Buhler (1990, p. 348-371).

Obnubilar as fronteiras entre o conhecimento natural e o sobrenatural foi fundamental para validar os testemunhos gentios da verdade cristã. Como afirma Settis (1985, p. 89-124) em um texto sobre a sibila Agripa, no seu tempo havia uma tradição divinatória que reconhecia nas sibilas um modelo insuperável de vaticínio natural, ainda que exercido entre os gentios, no entanto capaz de captar no mundo os presságios da redenção e do julgamento final. Mas, para representar os julgamentos sibilinos como vaticínio natural seria necessária exatamente essa nuança entre os saberes naturais e sobrenaturais mostrada pelos autores que traçaram a história mitológica da astrologia, retornando às suas origens de revelação, combinando e emparelhando astrólogos e sibilas como testemunhos gentios da verdade cristã. 
No século XVI, ninguém menos do que Rafael e Michelangelo representaram sibilas em igrejas de incomensurável importância em Roma: Santa Maria da Paz e Capela Sistina, respectivamente. São dois exemplos que falam por si só, para dimensionar a importância dessas representações, mas não dão a dimensão numérica das representações das sibilas nas igrejas, na Itália. Em um espaço de poucas décadas, ao lado dos já citados pintores, destacam-se, entre os séculos XV e XVI nomes como Fra Angelico, Ghirlandaio, Andrea del Castagno, Raffaelino del Garbo, Veronese, Lorenzo Loto, Filippo Lipi, Bernardino Luini, Correggio, Dosso Dossi, dentre tantos outros que representaram as sibilas no mundo cristão. Neste contexto, não se pode compreender a profusão de imagens de sibilas, se não se recordar as intercorrências da contrarreforma, que pelo Concílio de Trento incentiva o uso das imagens numa reafirmação da carta que Gregório Magno enviou a Serenus, bispo de Marselha, por volta do ano 600, em resposta à destruição das imagens que fizera aquele religioso na sua paróquia. Conforme Besançon (1997, p. 243-244) Gregório Magno legitimava o uso das imagens por três caminhos distintos: como contribuição para o melhor entendimento das passagens da Bíblia, mormente para os não alfabetizados sem acesso à palavra de Deus por meio da leitura da Bíblia Sagrada; rememorar a vida dos santos mártires e de Jesus Cristo; e também, promover a humildade e o compunção da alma que se percebe pecadora. $\mathrm{O}$ concílio de Trento foi realizado em 1562 e com relação às imagens, retoma claramente as determinações de Gregório Magno:

as imagens não só recordam ao povo os benefícios e dons concedidos por Cristo, mas também expõem aos olhos dos fiéis saudáveis exemplos dos santos e dos milagres que Deus realiza com o fim de que a Ele deem graças e regrem sua vida e costumes pelo exemplo dos mesmos santos e assim se voltem para adorar e amar a Deus, praticando a piedade. (ARRIVABENE, 2008, p. 207).

Paralelamente aos determinantes do concílio, o uso didático das imagens sacras a partir de uma crescente valorização do naturalismo que evitasse a licenciosidade, os excessos de ornamento, a ignorância das escrituras, a artificialidade e a falta de decoro (equívocos mencionados no decreto tridentino) é 
legitimado e incentivado por tratados como os de Gabriele Paleotti e Borromeo. 3 Incentivados pelo ideário tridentino, pintores e escultores do barroco adornaram igrejas ao norte da Itália, destacando-se neste período as regiões da Emilia Romagna e da Lombardia 4.

Evidentemente se o incentivo ao uso das imagens se deu nomeadamente para Nossa Senhora, Jesus Cristo, santos e mártires, em nenhum momento estão mencionadas as imagens das sibilas que não são aludidas na bíblia a não ser em apócrifos, como afirma Magnani (2016, p. 122). Entretanto, se se compreende a necessidade persuasória da Igreja reformada, as sibilas, enquanto comunicantes com o divino e com o saber porvindouro, são extremamente eficientes nesse objetivo.

No final do século XVI manuais de iconologia foram criados, mas sem uma sistematização oficial por parte da Igreja. O exemplo mais importante é talvez, $A$ Iconologia, de Cesare Ripa (editado em 2012, de forma primorosa) que propõe descrições iconográficas de conceitos abstratos permitindo a criação de uma linguagem alegórica homogênea e universal na Europa de seu tempo (RIPA, 2012). Apesar de não constar a iconologia das sibilas neste manual, o abade Cesare Orlandi, em 1767, foi responsável por uma edição da Iconologia do Ripa acrescida de imagens, anotações e fatos, onde aparece a iconografia de 10 sibilas.

\section{Conclusão}

A análise astrológica da fé cristã fortalecida pelo entrelaçamento com as figuras conhecidas dos magos e das sibilas provar-se-ia imensamente poderosa e popular nos séculos XVI e XVII. No entanto, o século XVII, conhecido como o período da ciência moderna, traria muitas críticas tanto à astrologia quanto às profecias sibilinas. Diversos eruditos não hesitaram em tentar demonstrar que se

\footnotetext{
${ }^{3}$ Sobre os tratados de Borromeo e Paleotti, sugiro as leituras de Jones (1997) e Bianchi (2008).

${ }^{4}$ Vejam-se, como exemplo, as sibilas pintadas por Guercino na Catedral de Piacenza (GUERCINO A PIACENZA - VISTA DELLA CUPOLA, 2019).
} 
tratava de pura invenção. São exemplo dessa descrença as concepções de David Blondel e Isaac Casaubon, datadas de 1660 e sobre as quais nos informa Minois (2007, p. 351). Para Vossius as profecias sibilinas tratam-se de invencionice dos judeus. Para Johannes Marckius de Groninga trata-se de uma fraude atribuída aos padres. Para o holandês Antoine Vandale, as sibilas são malandras que não teriam previsto coisa alguma. A partir do final do século XVII os oráculos sibilinos foram sendo desmistificados e por volta de 1694 tornaram-se a base de um jogo para a sociedade nos Países Baixos. A profecia se torna um gênero literário de divertissement própria dos almanaques. A astrologia também se viu desacreditada, uma vez que a passagem do cometa de 1680, não devidamente prevista, criou ocasião para longos debates sobre a eficiência daquele saber no sentido de fazer previsões. Antes disso, porém, homens como Molière, La Fontaine, Bossuet, Fenelon desfecharam já ataques contra a astrologia. Por diferentes motivos bispos, teólogos, céticos e racionalistas questionaram a validade das previsões a partir das influências astrais. Não foi, no entanto, sem reação que os ataques sofridos às profecias sibilinas circularam. Exemplo disso, em 1678, Jean Crasset, pregador jesuíta, em sua Dissertation sur les Oracles des Sybilles faz a apologia dos oráculos sibilinos, atacando diretamente as críticas feitas por Blondel. Entretanto, a partir dos finais do século XVII são cada vez menores as ocorrências das representações das sibilas nas Igrejas na Itália, ainda que em menor número sejam representadas, por vezes de maneira meramente decorativa, até o século XX. Exemplos monumentais são as quatro sibilas pintadas por Achille Casanova na Basílica de Santo Antônio em Pádua, na primeira metade do século. Também os símbolos do zodíaco continuaram a comparecer nas igrejas. Podemos citar o Santuário de São Geraldo em Curvelo, Minas Gerais, criado pelos redentoristas no início do mesmo século, conforme nos assevera Neto (2006, p. 95), que tem pinturas parietais com os símbolos do zodíaco.

A produção e circulação de gravuras desde o século XV permitiu ainda uma longevidade às pinturas das sibilas na Europa e nas colônias espanhola e portuguesa da América, como se pode conferir na primorosa obra de Raybould (2016, p. 06-255). Especialmente nas colônias ibéricas da América , foi a partir de 
gravuras holandesas da família Van der Passe, do primeiro quartel do século XVII, que as pinturas das sibilas foram feitas. As gravuras dos Van der Passe foram fartamente reproduzidas pelos franceses e tiveram fortuna na sua circulação. Ao menos dois ciclos foram dedicados às representações das sibilas.

O que fazem as profetisas pagãs no teto de uma igreja católica? Era a pergunta inicial. Os mitos antigos não morreram e sua sobrevivência foi asseverada na Igreja Católica por grandes nomes da teologia e da filosofia ao longo da história. A necessidade e o desejo de conhecer o futuro vão ao encontro das questões existenciais mais profundas do ser humano, de legitimação da vida e de compreensão da finitude. As sibilas e a astrologia permaneceram como permanece - parafraseando Ghelardi (2011, p. XV) - a questão humana mais ampla de orientação espiritual em face do universo e da vida.

\section{REFERÊNCIAS}

AgOstinho, Santo. A cidade de Deus. Petrópolis: Vozes, 2013.

AGUSTIN, San. Escritos Antimaniqueos ( $\left.\mathbf{2}^{\circ}\right)$ : contra Fausto. Madrid: Biblioteca de Autores Cristianos, 1993. (Obras Completas de San Agustin, 31).

ANDALORO, M. Atlante. Roma: Percorsi Visivi, 2006. p. 337-338.

ARRIVABENE, Talita Goulart. Usos e funções das imagens sob o ponto de vista da Igreja. Outros Tempos, v. 5, n. 6, p. 202- 225, dez. de 2008.

AVILÉS, Alejandro García. Alfonso X, Albumasar y la Profecia del Nacimiento de Cristo. IMAFRONTE, Múrcia, n. 8-9, p. 189-200, 1992-1993.

BAIXAULI, M. L. et al. (org.). Fe y razón. Navarra: Ediciones Universidad de Navarra, 1999.

BARBIERI Filippo. Discordantiae sanctorum doctorum Hieronymiet Augustini; Sibyllarum et prophetarum de Christovaticinia. Disponível em:

http://digi.vatlib.it/view/Membr.IV.29. Acesso em: 18 mar. 2019.

BAUDOIN, Claudie. 4 vie di predisposizione alla divinazione in Mesopotamia e nel mondo Ellenistico. Parchi di Studio e Riflessione La Belle Idée, febbr. 2012. 
BESANÇON, A. A imagem proibida: uma história intelectual da iconoclastia. Rio de Janeiro: Bertrand Brasil, 1997.

BEZOLD, Friedrich Von. Astrologische Geschichtsconstruction im Mittelalter. Deutsche Zeitschrift für Geschichtswissenschaft Bd. 8 (1892), 29-71. In: AVILÉS, Alejandro García. Alfonso X, Albumasar y la Profecia del Nacimiento de Cristo. IMAFRONTE, Múrcia, n. 89, p. 189-200, 1992-1993.

BEZOLD, Friedrich Von; BOLL, Franz. Le stelle: credenza e interpretazione. Traduzione di Maurizio Ghelardi e Susanne Müller. Torino: Bollati Boringhieri, 2011.

BIANCHI, Ilaria. La politica delle immagini nell'età della Controriforma. Gabriele Paleotti teorico e committente. Bologna: Editrice Compositori, 2008.

BÍBLIA. Sagrada bíblia católica: Antigo e Novo Testamentos. Tradução de José Simão. São Paulo: Sociedade Bíblica de Aparecida, 2008.

BIBLIOTECA APOSTÓLICA VATICANA. Discordantiae Sanctorum Doctorum Hieronymi et Augustini. Disponível em: http://digi.vatlib.it/view/Membr.IV.29. Acesso em: o9 mar. 2018.

BOLL, Franz. Die Geburt des Kindes. Deutsche Literaturzeitung, n.s. XLV,1924, p. 769782. In: GHELARDI, Maurizio. Introduzione. Magia Bianca. In: BEZOLD, Carl; BOLL, Franz. Le stelle: credenza e interpretazione. Traduzione di Maurizio Ghelardi e Susanne Müller. Torino: Bollati Boringhieri, 2011.

BORROMEO, Carlos. Instrucciones de la fábrica y del ajuar eclesiásticos. México: Università Nacional Autonoma de México, 1985.

BOTTIN, F. (org.) La scienza sperimentale. Milano: Rusconi, 1990.

BROWN, Raymond E. A Quarta Bucólica de Virgílio. Ciberteologia: revista de teologia \& cultura, ano 3, n. 9, jan./fev. 2007. Disponível em:

https://ciberteologia.com.br/post/notas/a-quarta-bucolica-de-virgilio. Acesso em: 11 nov. 2019.

BUHLER, Stephen M. Marsilio Ficino's De Stella Magorum and Renaissance views of the Magi. Renaissance Quarterly, v. 43, n. 2, p. 348-371, Summer 1990.

CASTIÑEIRAS, Manuel. Da Virgilio al Medioevo: postille sulla rinascita della Sibilla in Campania (XI-XIII secolo). Arte Medievale, Milano, IV serie, anno 6, p. 97-110, 2016.

CECCHELLI, C. I mosaici della basilica di S. Maria Maggiore. Torino 1956, p. 213-219. In: CASTIÑEIRAS, Manuel. Da Virgilio al Medioevo: postille sulla rinascita della Sibilla in Campania (XI-XIII secolo). Arte Medievale, Milano, IV serie, anno 6, p. 97-110, 2016.

CONSTANTINO. Ad Sactum Coetum 19 (Or. Sib.8.2.217;243). In: PARKE, William Herbert. Sibille. Genova: Edizioni Culturali Internazionali, 1992. 
CRASSET, R. P. J. Dissertation sur les oracles des sybilles. Paris: E. Michallet, 1678. Disponível em:

http://gallica.bnf.fr/ark:/12148/bpt6k9614528k.r=sibylles\%2oblondel?rk=21459. Acesso em: 10 mar. 2018.

DEMPSEY, Charles. Baccio Baldini, Sibyls and Albumasar. In: MOREL, Philippe (dir.). L'art de la Renaissance entre science et magie. Rome: Académie de France a Rome, 2006. p. 85-98.

ELIADE, Mircea. Mito e realidade. São Paulo: Perspectiva, 1972.

FERRI, Silvio. La sibilla e altri studi sulla religione degli antichi. Pisa: Edizone ET, 2007.

GASPARRO, Sfameni Giulia. La sibila: voce del Dio per pagani, ebrei e cristiani: un modulo profetico al croce via delle fede. In: CHIRASSI, Ileana; SEPPILLI, TuLlio (éd.). Sibille e linguaggi oracolari: mito, storia, tradizione. Atti del convegno MacertaNorcia, 20-24 settembre 1994, Macerata. Pisa: Instituti Editoriali e Poligrafici Internazionali, 1999. p. 505-553.

GHELARDI, Maurizio. Introduzione. Magia Bianca. In: BEZOLD, Carl; BOLL, Franz. Le stelle: credenza e interpretazione. Traduzione di Maurizio Ghelardi e Susanne Müller. Torino: Bollati Boringhieri, 2011.

GIUSTINIANI, Giulia. Gli esordi critici di Emile Mâle: la tesi in latino sulle sibille. Mélanges de l'École française de Rome - Moyen Âge [Online], v. 125, n. 2, 2013. Disponível em: https://journals.openedition.org/mefrm/1527. Acesso em: 18 mar. 2019.

GUERCINO A PIACENZA - VISTA DELLA CUPOLA. Disponível em: http://www.marcostucchi.com/Panoramiche/VirtualTour/GuercinoPiacenza/tour.html?st artscene=scene_GuercinoPiacenza_VistaCupola. Acesso em: 13 mar. 2019.

HERÁCLITO. Fragmentos. In: OS PRÉ-SOCRÁTICOS. Tradução de José Cavalcante de Souza et al. São Paulo: Abril Cultural, 1996. (Coleção Os Pensadores).

JONES, Pamela M. Frederico Borromeo e l'ambrosiana: arte e riforma cattolica nel XVII secolo a Milano. Milano: Vita e Pensiere, 1997.

LACTANCIO. Instituiciones divinas. Tradução de E. Sánchez Salor. Madrid: Editorial Gredos, 1990.

LERNER, R. E. Medieval Prophecy and Religious Dissent. Past and Present, n. 72, p. 324, agosto 1976.

MAGNANI, M. C. A. O. Sibilas: da Babilônia ao Brasil. Revista Portuguesa de Humanidades, Braga, v. 20, n. 2, p. 115-138, 2016. 
MAGNANI, M. C. A. Os véus nas pinturas e as pinturas nos véus: as sibilas dos panos quaresmais de Diamantina. In: MATTOS, André Borges de et al. (org.). Ciências humanas em foco. Diamantina: UFVJM, 2017. p. 177-198. Disponível em http://acervo.ufvjm.edu.br/jspui/handle/1/1521. Acesso em: 18 mar. 2019.

MÂLE, Émile. Quomodo sibyllas recentiores artifices repraesenta verint. Paris: E. Leroux, 1899.

MÂLE, Émile. L'art religieux du XIIIe siècle en France. Paris: Librairie Armand Colin, 1912. Disponível em: https://archive.org/details/lartreligieuxduoomluoft. Acesso em: 18 mar. 2019.

MATERNO, Firmico. Mathesis, 1, 10, 14; 5, praef.3. In: BEZOLD, Carl; BOLL, Franz. Le stelle: credenza e interpretazione. Torino: Bollati Boringhieri, 2011.

MAURY, Paul. Le secret de Virgile et l'architecture des Bucoliques. Lettres d'Humanité, Paris, n. 3, p. 71-147, 1944.

MINOIS, Georgis. Storia dell'avvenire: dai profeti alla futurologia. Bari: Edizione Dedalo, 2007.

MOMIGLIANO Arnoldo. Dalla sibilla pagana alla sibilla cristiana: profezia come storiadellareligione. Analle della Scuola Normale Superiore di Pisa, Pisa, v. 17, n. 2, p. 407-428, 1987.

NETO, L. D. Das terras baixas da Holanda às montanhas de Minas: uma contribuição à história das missões redentoristas durante os primeiros trinta anos de trabalhos em Minas Gerais. 2006. Tese (Doutorado em Ciência da Religião) -Universidade Federal de Juiz de Fora, Juiz de Fora, 2006.

NORTH, J. D. Astrology and the fortunes of churches. Centaurus, v. 24, n. 1, p.181-211, 1980.

ORLANDI, Cesare. Iconologia del cavaliere Cesare Ripa. Notabilmente acresciuta d’immagini, di annotaizoni e di fatti. Perugia: Nella Stamparia di Piergiovanni Costantini, 1767. Disponível em:

https://archive.org/details/iconologiadelcavo4ripa/page/n4/mode/2up. Acesso em: 18 mar. 2019.

PARERA, Leticia Bañares. El conocimiento profético, entre la razón y la fe. In: BAIXAULI, M. L. et al. (org.). Fe y razón. Navarra: Ediciones Universidad de Navarra, 1999. p. 171176.

PERETTI, Aurelio La sibilla babilonese nella propaganda ellenistica. Firenze: La Nuova Italia Editrice Firenze, 1943.

RAYBOULD, Robin. The sibyl series of the fifteenth century. Boston: Brill Editors, 2016.

RIPA, Cesare. Iconologia. Torino: Giulio Enaudi Editore, 2012. 
ROSSI, Angelina. Le sibille nelle arti figurative italiane (con sette illustrazioni nel testo). L'arte: rivista di storia dell'arte medievale e moderna, Roma, v. 18, p. 272-285, 1915b.

ROSSI, Angelina. Le sibille nelle arti figurative italiane (con tre illustrazioni nel testo). L'arte: rivista di storia dell'arte medievale e moderna, Roma, v. 18, p. 209-221, 1915a.

SADAN. I segreti astrologici di Albumasar. A cura di VESCOVINI, Gabriela Federici. Torino: Nino Aragano Editore, 2000.

SAXL, Fritz. La fede negli astri: dall'Antichità al Rinascimento. Torino: Bollati Boringhieri, 2016.

SAXL, Fritz. La storia delle immagini. Bari: Editore Laterza, 1982.

SAXL, Fritz; PANOFSKY, Erwin. Mitología clásica en el arte medieval. Buenos Aires: Sans Soleil, 2016.

SETTIS, Salvatore. Presentazione. SEZNEC, Jean. La sopravvivenza degli antichi dei: saggio sul ruolo della tradizione mitológica nella cultura e nell'arte rinascimentali. Torino: Bollati Boringhieri, 2015.

SETTIS, Salvatore. Sibilla Agripa. Etudes de Lettres: revue de la Faculté des Lettres de Lausanne Université, v. 4, p. 89-124, 1985.

SEZNEC, Jean. La sopravvivenza degli antichi dei: saggio sul ruolo della tradizione mitológica nella cultura e nell'arte rinascimentali. Torino: Bollati Boringhieri, 2015.

SOUZA, Ronaldes de Melo e. O narrador epilírico de "Campo Geral”. Diadorim, Rio de Janeiro, v. 1, p. 63-74, 2006.

THÉREL, M.-L. Une image de la sibylle sur l'arc triomphal de Sainte-Marie-Majeure à Rome. In: CASTIÑEIRAS Manuel. Da Virgilio al Medioevo: postille sulla rinascita della Sibilla in Campania (XI-XIII secolo). Arte Medievale, Roma, IV serie, anno VI, p. 97-110, 2016.

TOMÁS DE AQUINO, Santo. Suma teológica: volume 7, seção 2, parte 2, questões 123189. São Paulo: Edições Loyola, 2002.

WARBURG, Aby. A renovação da Antiguidade pagã. Rio de Janeiro: Contraponto, 2013.

WARBURG, Aby. Opere I. La rinascita del paganesimo antico e altri scritti (18891914). Torino: Nino Aragno Editore, 2008. 